\title{
MEDICAL SOCIETIES.
}

THE teNnessee state drediCAL association.

The Seventy-seventh Annual Meeting of the Tennessee State Medical Association was held in Memphis, April 12-14. The program presented was one of unusual interest. Perhaps the leading feature of the program, as to public importance, was an open session on the evening of the first day of the meeting. This session was devoted to the discussion of the hookworm disease. The association and the public in general were fortunate in having an opportunity to hear a presentation of this subject by Dr. Chas. IV. Stiles, of the United States Marine Hospital Service, who has been for some years interested in this question and has devoted a large amount of time and labor in investigating its origin, its distribution, its symptoms and general clinical manifestions as well as the best methods of contending with this rather wide-spread disease. The symtomatology and diagnosis of the disease was discussed by Dr. George Dock, of Tulane University, who presented this phase of the question in a most interesting way, both to the public and the profession. In addition to these distinguished visitors, Dr. Louis Leroy, of Memphis; Dr. G. Newton Evans, of Nashville, and Dr. William Litterer, of Nashville, read papers upon the various phases of the subject, such as clinical manifestations, pathology and study of the non-oviparous female hookworm. Dr. Litterer's remarks were especially directed to the latter phase of this question. Pellagra with reports and exhibition of cases also contributed largely to the interest of the meeting. In addition to these special features which are now commanding so much attention on the part of the public. the health authorities and the profession in general, the program was one replete with interest to each and every member of the profession, giving as it did a large number of special subjects. There were also interesting papers with special reference to questions involved in medical education and higher standards of medical education.

Although the attendance was not so large as had been anticipated and all papers appearing on the program were not presented, yet the meeting was one of peculiar interest and afforded ample opportunity for everyone present to either give expression to his views or to reap a rich harvest from views and experiences of others.

The officers elected at this session for the present year were as follows: President, Dr. J. A. Witherspoon, Nashville; Vice Presidents, Dr. J. J. Waller, East Tennessee, Oliver Springs; Dr. R. A. Barr, Middle Tennessee, Nashville; Dr. Eugene Rosamond, West Tennessee, Memphis; Secretary-Editor, Dr. Geo. H. Price, Nashville; Treasurer, Dr. W. C. Bilbro, Murfreesboro; Delegate to the American Medical Association, Dr. L. A. Yarbrough, Covington; alternate, Dr. J. D. Brewer, Newbern; Dr. S. S. Crockett, Nashville; alternate, Dr. L. M. Woodson, Gallatin; Dr. S. R. Miller, Knoxville; alternate, Dr. B. D. Bosworth, Knoxville. Board of Trustees of Journal, Dr. W. C. Bilbro, Murf́reesboro; Dr. E. C. Ellett, Memphis; Dr. B. D. Bosworth, Knoxville.

XASHVILLE ACADEMY OF MEDICINE AND DAVIDSON COUNTY MEDICAL SOCIETY.

The annual meeting of the Academy occurred on the second Tuesday of April, at its home in the Carnegie Library Assembl, Room.

The retiring President, Dr. Duncan Eve, delivered the annual address, and chose for his subject the "Treatment of Fractures." He has been for so long an authority upon this subject that his address was listened to with marked interest. It was a comprehensive, yet practical discussion of an important question that reflected great credit upon the distinguished writer. 
The election of officers resulted as follows: President, Dr. J. M. King; Vice-President, Dr. Robt. Caldwell; Secretary; Dr. W. C. Dixon.

The ensuing year's prograni promises to be a very attractive one, and the Academy hopes to enter upon an increased era of usefulness. A high class of scientific work has been accomplished during the last year, and with renewed interest and activity, a larger measure of efficiency has been attained.
The Library feature, including all of the latest medical journals, is increasing iil popularity, and serves even an additional degree of helpfulness to the profession of Nashville and Davidson County.

The annual banquet which the Academy would have had on this occasion was deferred on account of the death of one of its ExPresidents and most enthusiastic members, Dr. J. Y. Craw ford.

\section{BOOK REVIEWS}

Listing of books and pamphlets recelved is considered full compensation. Reviews will be made at the discretion of the staff.

Cosstipation and I.stestinal Onstructiox.

By Samuel Goodwin Gant, M.D., LL.D., with 250 original illustrations. Published by IV. B. Saunders Co.

This treats of "the American disease" in an American fashion. It would be difficult to overestimate the value of this work if properly understood and practiced by the profession as a whole. It might be described as the drugless treatment of constipation and obstipation. The drug treatment of these disorders, by the plysicians is unsatisfactory enough, but by the patient it may be exceedingly harmful. Especial attention is paid in this work to the chronic obstructions, not serious enough to urgently demand surgica! relief, and still so severe that ordinary measures against constipation are futile. This work, however, contains a rather complete description of the so-called medical treatment, but the greatest stress is placed upon adequate examination, to determine which of the several factors are responsible for the given case. There is no one cause, and no one treatment, but many causes, and each should have its appropriate remedy. A careful effort is made to discriminate clinically between constipation and obstipation. The former exists year in and year out, while in chronic obstruction con- stipation alternates with diarrhea. Sometimes one complains of mucous and blood, and frequently fragments of tissue. Purgation increases peristalsis, and hence increases the pain, because of the inability to pass tlie obstruction which is always at a definite point. Chronic mechanical obstruction occurs mostly in middle life, or old age; begins suddenly, usually follows ulceration of the bowels, operations, typhoid fever, appendicitis or peritonitis.

There has been an erroneous impression among some practitioners with regard to fecal impaction. It is nearly always in the rectum. or descending colon, is a chronic condition, and rarely acute. It seems incredible that men could consider this as an explanation of acute cases of appendicitis, or real intestinal obstruction. In considering treatment, the allthor expresses it as "no light task, and in order to cure chronic constipation, in its various aspects, physicians must possess great patience, ingenuity, exceptional diagnostic ability, and most thorough medical training." Prescription treatment is notoriously disappointing.

The dietetic treatment is discussed fully, as is also exercise and bodily movement, together with hydrotherapy externally, also internally. Massage is given its full place, and mechanical 